\title{
Amalia en el cine: 1936, la conquista de la ciudad
}

Amalia in the Cinema: 1936, the Conquest of the City

Amalia no cinema: 1936, a conquista da cidade

\section{Nicolás Suárez}

UNIVERSIDAD DE BUENOS AIRES / CONSEJO NACIONAL DE INVESTIGACIONES CIENTÍFICAS Y TÉCNICAS (CONICET), ARGENTINA

Licenciado en Letras por la Universidad de Buenos Aires. Becario del Conicet y doctorando en Literatura por la Universidad de Buenos Aires, con un proyecto de investigación sobre las versiones cinematográficas de textos de la literatura argentina decimonónica. Es autor de Vida y obra de Sarmiento en el cine (ganador del Concurso Nacional y Federal de Estudios sobre Cine Argentino Biblioteca ENERC-INCAA, Ciccus, 2017). Guionista y director de cine licenciado en la Escuela Nacional de Experimentación y Realización Cinematográfica. Correo electrónico: nicola_suarez@yahoo.com.ar

Artículo de investigación

Documento accesible en línea desde la siguiente dirección: http://revistas.javeriana.edu.co 


\section{Resumen}

El artículo propone una lectura comparativa de la novela Amalia (1851/5) de José Mármol y su transposición cinematográfica homónima, dirigida por Luis José Moglia Barth en 1936. Estrenada en el marco de las celebraciones por el cuarto centenario de la primera fundación de Buenos Aires, la película supone un modo de distinción, en tanto recupera de la novela la idea de la ciudad como epítome de la nacionalidad, para ofrecer un modelo de nación alternativo al entonces propuesto por los imaginarios del criollismo y el tango.

Palabras clave: Amalia; José Mármol; Luis José Moglia Barth; transposición; 1936;

Buenos Aires

\section{Abstract}

The article proposes a comparative reading of José Mármol's novel Amalia (1851/5) and its homonymous film transposition, directed by Luis José Moglia Barth in 1936. Released during the celebrations for the $400^{\text {th }}$ anniversary of the first settlement of Buenos Aires, the movie involves a desire for distinction since it revisits the idea of the city as epitome of the nation, in order to offer an alternative model of Argentine identity that differs from the imaginaries of criollismo and tango.

Keywords: Amalia; José Mármol; Luis José Moglia Barth; transposition; 1936;

Buenos Aires

\section{Resumo}

$\mathrm{O}$ artigo propõe uma leitura comparativa do romance Amalia (1851/5) de José Mármol e sua transposição cinematográfica homônima, dirigida por Luis José Moglia Barth em 1936. Estreada no marco das comemorações pelo quarto centenário da primeira fundação de Buenos Aires, o filme supõe um modo de distinção, em tanto recupera do romance a ideia da cidade como epítome da nacionalidade, para oferecer um modelo de nação alternativo ao então proposto pelos imaginários do crioulismo e o tango.

Palavras-chave: Amalia; José Mármol; Luis José Moglia Barth; transposição; 1936;

Buenos Aires 
Durante LaS PRIMeras décadas del siglo XX, Amalia de José Mármol fue objeto de diversas transposiciones que incluyen versiones de la novela en soportes tales como el teatro, la fotonovela, el cine y la canción popular. ${ }^{1}$ En 1936 Luis José Moglia Barth, director de éxitos como Tango! (1933) y Riachuelo (1934), añade un eslabón más a esta cadena. La segunda versión cinematográfica de Amalia se estrenó el 8 de julio en el Cine Monumental de la calle Lavalle. Como señala un cronista de la época, se eligió "la víspera de la gloriosa fecha patria" para darle al estreno "mayor carácter nacionalista" ("Amalia, el romance histórico"). Esa fecha patria, el 9 de julio, fue también adoptada para dar nombre a una avenida cuya construcción se había iniciado en abril del mismo año. En esa misma avenida, en el mes de mayo y a escasas cuadras del Cine Monumental, se inauguró el obelisco, monumento que señala el punto álgido de las celebraciones del cuarto centenario de la fundación de Buenos Aires por Pedro de Mendoza.

Estrenada en este contexto de celebración y modernización de la ciudad, la versión de Amalia de Moglia Barth puede pensarse como un hito más dentro de ese jubileo que -en palabras de Adrián Gorelik- duró todo 1936, "con inauguraciones de obras e iniciativas en las que la historia tuvo [...] un rol decisivo" (418). Sin embargo, no todo entonces era celebración. Como indica Beatriz Sarlo, la Argentina que en el siglo XIX era una causa y un programa, a mediados de la década de 1930 aparece como un problema que admitía pocas soluciones optimistas (Una modernidad 242) (el proceso de industrialización, el crecimiento de las masas populares y el regreso de la democracia restringida son síntomas de ello). Frente a este momento vivido como crítico y en busca de un principio de orden, emerge lo que Sarlo denomina la "imaginación histórica", entendida como un tipo de

$1 \quad$ El 21 de mayo de 1904 fue publicada en Caras y Caretas una adaptación de Amalia en formato de fotonovela. En noviembre del mismo año se estrenó en el Teatro de la Comedia un drama histórico en siete actos escrito por Julio Castellanos y basado en la novela de Mármol, que sería publicado catorce años más tarde en la revista teatral Bambalinas. En 1914 Enrique García Velloso presentó en el Teatro Colón una versión cinematográfica de Amalia, que además fue acompañada por la publicación de un folleto en el que se incluía una biografía de Mármol y el guion de la película ilustrado con fotos. El 6 de julio de 1929 se estrenó en el teatro Liceo La Rosa de sangre, un poema dramático en verso basado en la Amalia de Mármol y también publicado en Bambalinas. En 1936 García Velloso transpuso una vez más Amalia, esta vez en su faceta de dramaturgo. Dos años después se publicó la partitura de "La canción de Amalia", un vals grabado en 1933, con versos de Héctor Pedro Blomberg y música de Enrique Maciel. Tomo estos datos de la Contribución a la bibliografía de fosé Mármol (1972), de Juan Carlos Ghiano. 
discurso que, sin ser estrictamente historiográfico, recurre a la explicación histórica para definir hipótesis sobre el pasado y lanzarse a probabilidades futuras (207). Son estos los años en que se dan a conocer obras como Evaristo Carriego (1930) de Jorge Luis Borges, El hombre que está solo y espera (1931) de Raúl Scalabrini Ortiz, Radiografía de la Pampa (1933) de Ezequiel Martínez Estrada, El paso de los Libres (1934) de Arturo Jauretche e Historia de una pasión argentina (1937) de Eduardo Mallea, que corren en paralelo con la labor del grupo de intelectuales nucleados en torno a la Fuerza de Orientación Radical de la Joven Argentina (FORJA) y con el surgimiento del primer revisionismo, que emplea la experiencia rosista como cartabón para medir los logros de la etapa siguiente (Halperin Donghi, El revisionismo 51). También en diálogo con estos discursos sobre la historia nacional puede pensarse la película Amalia.

No obstante, hay algo del orden de lo singular que le otorga al filme un lugar diferencial dentro de la configuración discursiva de la imaginación histórica: la película participa del debate sobre la historia, pero a la vez se inscribe en esa suerte de programa romántico inaugurado por Amalia, que promovía la novela como "ficción fundacional" de la nacionalidad (Sommer Ficciones fundacionales) y luego quedó clausurado (Laera, El tiempo vacío 16). Así, al privilegio que ostenta Amalia de ser la primera novela argentina, la primera obra narrativa en la que "la ciudad de Buenos Aires aparece en forma integral" (Dámaso Martínez 285) y el primer largometraje nacional (en la versión de 1914), Moglia Barth le agrega el de inaugurar en Argentina el sistema de sonido RCA Victor y ser la primera superproducción de Argentina Sono Film (tal como se publicita la película en el afiche). En distintos órdenes, pues, Amalia reviste un carácter singular, ya que participa de la generalidad de una serie pero desde la particularidad de una posición diferencial. ${ }^{2}$

\section{Lo popular en disputa}

La apelación a Amalia como forma de distinción no era nueva y ya había sido practicada en la versión cinematográfica de 1914 dirigida por Enrique García Velloso, en el contexto de repliegue de una élite en condiciones de pérdida de poder político. Dos décadas después, en el mismo año en que García Velloso estrena una versión teatral de Amalia, Moglia Barth vuelve a acudir

2 La pregnancia de esta lectura se advierte en una convocatoria reciente del Instituto de Cine y Artes Audiovisuales (INCAA) para la realización de cinco cortometrajes, en el marco de la conmemoración de los cien años del estreno de Amalia, primera película nacional de ficción. 
a la novela de Mármol con el objetivo de trazar distancias. Tal como se desprende de un relevo de fuentes periodísticas, esto es valorado positivamente por numerosos críticos, para quienes Amalia "se destaca sobre el cuadro de las últimas películas criollas" ("Por su realización") y se aparta "del tango y sus odiosas adyacencias" ("Estrenose ayer Amalia").

Esa pretensión se percibe ya desde las estrategias de comercialización. Los avisos publicados en los diarios durante la semana del estreno se refieren al filme como "La más regia película argentina", "Estreno de lujo" o "La película más perfecta del cine argentino". Incluso las innovaciones sonoras fueron percibidas por la prensa desde esta perspectiva, como un refuerzo de "la sensación de superioridad" ("La versión"). Pero el ámbito en el que la voluntad distintiva se hace más notoria probablemente sea el uso de la música. La elección más esperable para un director como Moglia Barth, en cuya filmografía el tango había ocupado hasta entonces un lugar destacado, ${ }^{3}$ hubiera sido optar por una articulación entre la temática histórica y la música popular. Esta opción incluso contaba con antecedentes en la época. A lo largo de la década de 1930, el cantante Ignacio Corsini interpretó un considerable repertorio de obras compuestas por el poeta Héctor Pedro Blomberg y el guitarrista Enrique Maciel, en las que se tematizaba el periodo rosista. La más conocida de estas piezas es "La pulpera de Santa Lucía", pero también se puede destacar la existencia de un vals titulado "Canción de Amalia", grabado en 1933, en el que se reproducen en tono elegíaco los sucesos narrados en la novela de Mármol. La variedad genérica que involucraba el ciclo federal de Ignacio Corsini le hubiera ofrecido a Moglia Barth una nutrida gama de alternativas para musicalizar su película, pero este sin embargo decide apartarse de ese camino y encarga la música del filme al compositor sinfónico y operístico Enrique Mario Casella.

Una crítica publicada en el Heraldo del Cinematografista resulta significativa para ponderar estas cuestiones. Dicha revista, dirigida a exhibidores cinematográficos, se consagraba a evaluar las posibilidades comerciales de las

Tango! (1933) fue no solo la primera película sonora argentina sino también un verdadero éxito de público, en buena medida gracias a que para mucha gente significó la oportunidad de ver cantar a las estrellas que hasta entonces solo eran conocidas por su voz. Moglia Barth luego repetiría la fórmula en Dancing (1933) y Riachuelo (1934), conformando de esa manera una trilogía articulada en torno a la temática tanguera y a la continuidad de un sistema productivo que permitía encarar el rodaje de una película mientras se estaba terminando la anterior (aunque esto último solo se alcanzó dificultosamente, debido al fracaso de Dancing en la taquilla). 
películas, a las que otorgaba un puntaje en diferentes áreas: valor argumental, valor artístico y valor comercial. En el caso de Amalia, en el valor comercial aparece una calificación inusual: "ver análisis". Podemos preguntarnos, entonces: ¿por qué evadir la calificación, si el texto destaca el "considerable valor comercial" de la película? ("Amalia").

La tendencia a la singularización formaba parte de las intenciones de Moglia Barth al adaptar la novela. En este sentido, la película puede abordarse a partir de la idea de que, ante el desgaste del imaginario del tango y el sainete criollo que el propio Moglia Barth había contribuido a formar en sus filmes anteriores, la transposición de Amalia supone un intento de construir una imagen alternativa de la nación a través de una imagen de la ciudad, en tanto epítome de la nacionalidad. Al basar esta operación en una adaptación de la novela de Mármol, la película estaría adscribiendo a la lectura entonces vigente de Amalia como un texto popular. Pero en esa percepción de la novela se confunden la popularidad dada por las numerosas adaptaciones del texto (lo popular como aquello que resulta conocido) y la popularidad propia de una historia de amores encontrados con trasfondo político ${ }^{4}$ (lo popular como aquello que es cercano al pueblo).

Esta doble noción de lo popular se puede rastrear tanto en la prensa de la época como en el filme. En diferentes publicaciones la película es mentada como una "adaptación de la popular novela" ("La versión") o de la "divulgada novela romántica" ("Amalia"), que era "ampliamente conocida por el libro y por las adaptaciones que de ella se han realizado" ("Estrenose ayer Amalia"). Asimismo, la propia obra exhibe su condición hipertextual: para

Tal sería, por ejemplo, el atractivo de Amalia para los lectores de la adaptación en fotonovela publicada en Caras y Caretas. "Pero además de su evidente popularidad -sostienen Guillermo Saccomano y Ema Wolf (33)- la importancia de Amalia reside en que fue una novela-molde. Por lo menos hasta fines del siglo XIX muchas de sus congéneres fueron construidas siguiendo [...] su estructura, su estilo alambicado y su decidida posición antirrosista". A comienzos del siglo Xx, esta tendencia es continuada en otros soportes, como el teatro, el radioteatro y el cine. La película Bajo la santa federación (1935), primer largometraje del popular realizador Daniel Tinayre, estaba basada en el folletín radioteatral homónimo de Héctor Pedro Blomberg y Carlos Max Viale Paz. El éxito de esta obra fue tal que "también inspiró copias en otras estaciones, incluyendo los trabajos subsecuentes de Blomberg y Viale Paz que repitieron la exitosa fórmula" (Karush 97). Así, todavía en el siglo XX, a través de sus diversas ramificaciones y en tanto primera novela nacional, la Amalia de Mármol sigue siendo, para decirlo con César Aira, una "representación única de la multiplicidad" (35). 
que el público no tenga dudas de que se trata de una adaptación de un texto literario, los créditos iniciales se presentan como páginas de un libro que van pasando y, cuando concluye el filme, aparece la última página de ese libro con la palabra "Fin" impresa.

En cuanto a la noción de lo popular en tanto cercanía respecto del pueblo, pueden destacarse dos reenvíos que realiza la película: uno metatextual y otro contextual. El primero de ellos ocurre mientras Eduardo reposa en la cama y Amalia le lee un pasaje de un libro. Sin embargo, el pasaje corresponde a la propia novela Amalia, por lo que se trata de una soterrada puesta en abismo. ¿Y qué elige leer Moglia Barth en la novela? Un fragmento que reza: "Abrió los ojos y derramó de ellos, húmedos y melancólicos, un mar de luz parecida a la que vierten los crepúsculos de una tarde lánguida del mes de enero" (138). Es decir, los elementos bajos, sentimentales, pasionales: el kitsch (entendido como ese momento en que la cultura de masas hace el gesto de la alta cultura). ${ }^{5}$ Este repliegue de la película sobre la novela da cuenta de la lectura del texto de Mármol que propone el filme: al sustituir las lecturas románticas de Amalia por un fragmento de la propia novela, Moglia Barth confunde la novela con esas lecturas románticas y borra la operación crítica del romanticismo que realiza Mármol. Esa operación, que según David Viñas ("Mármol y los dos ojos del romanticismo") consiste en una versión no integradora sino antinómica del romanticismo y que Alejandra Laera entiende más bien como una puesta en tensión de los postulados románticos ("El ángel y el diablo" 104), se diluye hacia el final del texto cuando Daniel acude a su padre federal en busca de ayuda y se impone la política conciliatoria post-Caseros. Justamente ese espíritu final es el que selecciona Moglia Barth al privilegiar la ficción amorosa por encima del tono realista. Es por eso que en la película el protagonista masculino interpretado por la estrella Delbene es Eduardo (el personaje romántico) y no Daniel (que en la novela desplaza a su amigo del protagonismo político y lo relega a la historia de amor). ${ }^{6}$ Esta

5 Una sensibilidad que hoy reconoceríamos como telenovelesca y que en la época era cercana a la de los folletines sentimentales estudiados por Beatriz Sarlo (El imperio de los sentimientos) o a la de las novelas radioteatrales. Recordemos que Florentino Delbene y Herminia Franco, que en la película encarnaron los personajes de Eduardo y Amalia, fuera de la pantalla -además de ser pareja- eran destacados actores de radioteatro y llegaron incluso a compartir elenco en algunas obras como La dama de las camelias, emitida en 1938 por Radio Belgrano.

6 Un reseñista se hace eco de esta cuestión y anota: "El reparto hubiera estado mejor con Delbene en el papel de Daniel y Raquen en el de Eduardo Belgrano" (Imágenes, 17 jul). 
elección de la trama amorosa en lugar de la histórico-política se corresponde con una lectura de la novela que se pretende despolitizada, pero que en rigor parece ser una forma de hacer política contraponiéndose a ella. ${ }^{7}$

El segundo reenvío, de carácter contextual, sucede mientras Eduardo observa un candombe federal en la calle y sostiene: "Para esta gente, no vivimos en una época de terror." Daniel le responde: "Es una influencia de la fiesta patria de mañana. Así es este pueblo porteño que tan fácilmente pasa del llanto a la risa, de lo grave a lo pueril y de lo grande a lo pequeño." La alusión a "la fiesta patria de mañana", que en la novela es el 25 de mayo pero en el filme carece de indicaciones precisas, nos devuelve al estreno en la víspera del 9 de julio y reinstala en un contexto diferente la oposición entre Rosas y Daniel, en tanto emergentes de un pueblo y un público que la novela y la película procuran definir. ${ }^{8}$

De esta manera, al intentar incorporar a la concepción de Amalia como un texto popular/mediático la capacidad de interpelar a las clases populares, la película se presentaría como una alternativa al tango y el criollismo, en tanto imaginarios que ostentan esa doble condición de lo popular. Para dar una idea del predominio de estos imaginarios en el ambiente cultural de la época, pueden destacarse dos hechos cercanos al estreno de la película. El primero de ellos es la edición de la revista Caras y Caretas del 11 de julio de 1936. En conmemoración por el aniversario de la fecha patria, el número aparece enteramente dedicado a la evocación de "la figura del gaucho argentino, expresión del espíritu criollo que no ha logrado obscurecer la influencia extranjera, porque él está aún latente en nuestros campos y ha sido, además, cantado y enaltecido por poetas y escritores que supieron ahondar hasta la entraña del suelo patrio" (Caras y Caretas, 11 jul).

Otro parece buscar, fallido mediante, el tertium comparationis que defina al personaje creado por Moglia Barth y habla de un curioso "romance entre Amalia y Eduardo Bello" ("Amalia"; el énfasis es mío).

7 En Categorías de lo impolítico Roberto Esposito describe este fenómeno a través del concepto de antipolítica, que sería "la forma extrema, póstuma y acabada de la política moderna como manera, inevitablemente conflictiva, de neutralizar otro conflicto, más insostenible todavía" (14).

8 Esta lectura de la novela como escenificación de una disputa por establecer la articulación pueblo/nación aparece también en la edición de Sopena del año 1932, en cuya tapa se observan sendos retratos de Rosas y Urquiza, enmarcando un escudo de la República Argentina que constituye el objeto de la disputa. 
El segundo acontecimiento tuvo lugar el 17 de septiembre de 1936, cuando el realizador Nelo Cosimi estrenó su fuan Moreira, tercera versión cinematográfica inspirada en la novela de Eduardo Gutiérrez. La película, que había sido promocionada con fotografías del rodaje en el mencionado número de Caras y Caretas, contó con la labor del conocido letrista de tango y comediógrafo José González Castillo como guionista y de su hijo Cátulo como compositor musical, además de la participación de veinte guitarristas en escena y de Antonio Podestá en el papel del alcalde. Con base en esta fusión del imaginario del tango con un texto central de la literatura criollista tal como esta fuera definida en el seminal estudio de Adolfo Prieto (El discurso criollista), no parece desacertado pensar que el Moreira de Cosimi constituye una formalización $a$ posteriori de aquello a lo que la Amalia de Moglia Barth pretende oponerse. Todavía más si se tiene en cuenta que se trata de dos textos pertenecientes a diferentes tradiciones literarias (la literatura romántica y el criollismo), de las cuales pueden derivarse tanto diversos personajes arquetípicos (la mujer romántica y el gaucho criollo) como modelos de escritores (el poeta romántico ${ }^{9}$ y el escritor profesional).

Sin embargo, desde un punto de vista historiográfico, la distancia entre la novela de Mármol y la de Gutiérrez no es tan abismal como podría suponerse. ${ }^{10}$ Dicha distancia es la que va de 1852 a $1880::^{11}$ los treinta años

9 En los títulos iniciales la película es presentada como una adaptación de Amalia, "del poeta argentino José Mármol".

10 Lo mismo puede sostenerse desde el punto de vista de la historia del cine nacional. En 1927 Nelo Cosimi había dirigido una película titulada Unitarios y federales, cuyo argumento -según una reseña de La Razón- estaba "inspirado en la Amalia de José Mármol” (Neifert 49). El filme, al igual que la Amalia de 1936, estuvo protagonizado por Florentino Delbene, que en 1948 a su vez participaría de la versión de fuan Moreira dirigida por Moglia Barth. Herminia Mancini, por su lado, participó en las dos películas de 1936. Este verdadero rizo que conecta a Amalia con Moreira, envolviendo las filmografías de Cosimi y Moglia Barth, da cuenta de la permeabilidad con que el cine de la época, amparado en la popularidad de los textos, podía desplazarse a través de diversas tradiciones literarias.

11 La novela de Mármol comenzó a publicarse en Montevideo en 1851, en la sección literaria del periódico La semana. La publicación fue suspendida en febrero de 1852, cuando Mármol decide regresar a su patria tras la caída de Rosas en Caseros. Recién en 1855 la obra se editaría completa, en formato de libro, incluyendo algunas modificaciones realizadas por el autor en vistas a mejorar la parte ya publicada pero también a atenuar los roces entre los bandos en pugna. Para un análisis pormenorizado de los problemas textuales de Amalia, puede consultarse el estudio de Beatriz Curia ("Problemas textuales de Amalia de José Mármol"). fuan Moreira, en tanto, se publicó como folletín entre noviembre de 1879 y enero de 1880 en 
de discordia, según la conocida fórmula de Tulio Halperin Donghi (Una nación para el desierto), que van de la batalla de Caseros a la federalización de Buenos Aires. De una conquista de Buenos Aires a otra, esos treinta años de enfrentamientos facciosos se condensan y precipitan en 1936. Precisamente, la convergencia de las versiones cinematográficas de Amalia y fuan Moreira en el año del cuarto centenario de la primera fundación de Buenos Aires viene a señalar la precariedad del consenso alcanzado después de la discordia, ya que ese consenso no aseguraba la edificación de la nueva nación sino solo la instauración de un Estado que se suponía que era la herencia de la etapa rosista. Así, las tensiones entre unitarios y federales -que Mármol elabora de manera novelesca al postular una nación imaginada que ancla en la comunidad ausente de los exiliados- y la nostalgia del Moreira de Gutiérrez -que anhela una comunidad guerrera y una épica estatal inevitablemente destinadas a desaparecer con el avance de la Organización Nacional (Dabove 188)- todavía resuenan en los conflictos que experimenta la ciudad durante las primeras décadas del siglo XX.

\section{Juntos en la ciudad}

Este alejamiento de los imaginarios del tango y el sainete criollo que plantea la película conlleva asimismo una lectura de Amalia como origen frustrado de la identidad nacional. Porque recuperar ese texto que carece de genealogía y herencia (puesto que inaugura la serie de la novela argentina pero no tiene herederos inmediatos) supone una forma alternativa de resolver la tensión entre modernización y tradición: lo moderno no emanaría, como explica Florencia Garramuño (Modernidades primitivas) para el caso del tango, de un origen primitivo, sino de un origen civilizado que sería la tradición romántica. Para dar forma a esa imagen alternativa de la nación, la película propone, al igual que la novela, una elaboración de lo nacional a partir del epítome que encuentra en la ciudad y sus alrededores. Y si -de acuerdo a las formulaciones de Benedict Anderson- las naciones pueden pensarse como Comunidades imaginadas, esa imagen de Buenos Aires involucra entonces un modelo comunitario.

el diario La patria argentina. Es decir que para el público del diario la lectura de los sucesos narrados en la novela era contemporánea de los enfrentamientos entre Carlos Tejedor y Julio Argentino Roca por la sucesión presidencial de Nicolás Avellaneda, que desembocarían primero en la llamada Revolución de 1880 (considerada el último episodio de las guerras civiles entre las provincias argentinas y Buenos Aires) y ulteriormente en la federalización de Buenos Aires y la presidencia de Roca. 
Sin embargo, a raíz de la traumática experiencia del siglo XX, la noción de comunidad ya no puede abordarse a partir del sentido de soberanía que adquiere en los planteos de Anderson. Como apunta Jean-Luc Nancy, el hecho de que la más grande obra de muerte de la humanidad se haya llevado a cabo en nombre de la comunidad es lo que ha puesto fin a toda posibilidad de basarse sobre cualquier forma de lo dado del ser común (11). Esta perspectiva biopolítica introducida a finales del siglo XX, primero en Francia y luego en Italia, hoy ofrece un arsenal crítico y teórico altamente productivo para repensar la pregunta por la comunidad. En su libro Communitas Roberto Esposito redefine la comunidad como un conjunto de personas a las que une no una propiedad, sino un deber o una deuda (el munus) que los expropia de su subjetividad (29). El contrapunto semántico de la comunidad, así, sería la categoría de inmunización, en tanto beneficio que dispensa al sujeto de la expropiación comunitaria (39). De ahí que, siguiendo a Matthew Karush (Cultura de clase), podamos afirmar que al igual que gran parte de la actividad cinematográfica en Argentina durante las décadas de 1920 y 1930, la Amalia de Moglia Barth no contribuye tanto a forjar mitos de unificación nacional como a la generación de imágenes polarizantes y divisivas: dicho de otra manera, como todo modelo comunitario, implica una idea de inmunidad.

En el texto de Mármol, el ideal comunitario se condensa en un deseo de Eduardo, quien le dice a Daniel: "Viviremos juntos. Haremos en Barracas una magnífica casa" (206). En este punto, conviene recordar de manera sucinta el argumento de la novela. Daniel Bello es un joven acomodado que trata de liberar de la persecución rosista a su amigo Eduardo Belgrano, luego de que este participara de un intento frustrado de huir de Buenos Aires e incorporarse al ejército de Lavalle. Para protegerlo, Daniel lo refugia en la casa de su prima Amalia, que vive sola y aislada del mundo en una recoleta mansión del barrio de Barracas. Durante un tiempo, Amalia y Eduardo viven un idilio en esa quinta y se enamoran. Pero a pesar de las hábiles maniobras de $\mathrm{Da}$ niel, doña María Josefa Ezcurra -cuñada de Rosas- descubre el paradero de Eduardo. Acorralado, este se casa con Amalia y decide huir a Montevideo. Sin embargo, el plan se ve nuevamente frustrado por una partida de mazorqueros que irrumpen en la casa y asesinan a Eduardo, quedando incierta la situación de Amalia y Daniel, cuyas muertes no son seguras.

La historia de Amalia sería, pues, un intento fallido de pasar del vivir "completamente aislada" (24) al "viviremos juntos" (del debilitamiento de los lazos asociativos a la imaginación comunitaria). En efecto, tanto la novela como la película podrían concebirse como experimentaciones ficticias de esa 
interrogación que ocupó a Roland Barthes en sus últimos años: ¿cómo vivir juntos? La frustración, sin embargo, se consuma hacia el final de la historia, cuando la irrupción del padre de Daniel enfrenta el modelo comunitario de la familia con la utopía comunitaria imaginada por Amalia. ${ }^{12}$ Pero mientras que en la novela prevalece la incertidumbre respecto del éxito o fracaso de ambos regímenes comunitarios (si bien Eduardo muere, los destinos de Amalia y Daniel son inciertos), en la película Daniel y su prima Amalia logran salvarse gracias a la llegada salvadora de don Antonio Bello: frente a la utopía comunitaria, se impone la familia como forma represiva. ${ }^{13}$

En los dos casos, igualmente, el vivir juntos se figura como una utopía urbana y barrial (Torre 77), a partir de la localización de la comunidad imaginada en un lugar liminar de la ciudad: la quinta de Barracas, ubicada en el Bajo. En la novela esa zona se recorta de la ciudad "pintada toda de colorado" (545) gracias a la mirada romántica de Daniel, que desde el punto de vista privilegiado de "la alta barranca de Balcarce", contempla y constituye como paisaje "los valles floridos de Barracas" y "el gracioso Riachuelo" (132). En la película, en tanto, la quinta de Barracas se idealiza mediante el uso de música clásica, ${ }^{14}$ tomas panorámicas y planos generales (registrados por la cámara desde un punto de vista también elevado). El empleo del contraluz, además, sirve para resaltar la condición idílica del romance entre Amalia y Eduardo. En un momento, incluso, entre la imagen de los amantes captada en contraluz y la cámara, se interpone el flujo de agua de una fuente, lo cual brinda una sensación de armonía entre los hombres y una naturaleza que se muestra controlada.

Ambas formas de idealizar la zona de Barracas comportan un uso similar del anacronismo, en tanto procedimiento que permite pasar de una noción espacial a una noción temporal del vivir juntos. En el texto de Mármol, la alu-

12 Esto podría suponer una divergencia con lo que plantea Graciela Batticuore, para quien el "ideal de la familia romántica" se realiza de manera breve pero efímera en el capítulo octavo de la tercera parte de la novela (55). No hay contradicción, empero, sino solo una diferencia terminológica. Lo que Batticuore entiende por familia romántica -una experiencia de la "felicidad culta, donde el amor, la literatura y la política se juntan inevitablemente" (56)- es lo que aquí llamamos, en la estela barthesiana, utopía comunitaria.

13 Esta tendencia a la enfatización de lo familiar se observa de manera aún más palmaria en la versión teatral de Castellanos, en cuyo final Amalia y Eduardo mueren pero Daniel sobrevive.

14 Al trabajo ya mencionado del compositor Casella, se añade en algunos pasajes la dirección orquestal del alemán Hans Diernhammer, colaborador habitual de las películas de Sono Film de finales de la década del treinta. 
sión al general Lavalle como transeúnte de la barranca de Balcarce doce años antes que Daniel permite proyectar la cartografía punzó en una línea temporal imaginaria que conecta a los unitarios de Buenos Aires con el ejército de Lavalle. En el filme, en el contexto de la industrialización y la emergencia de la zona portuaria del Riachuelo como locus del desarrollo económico durante la década de 1930, la configuración de la quinta de Barracas como un locus amoenus también supone un montaje de tiempos heterogéneos: la película vivió junto con (en el sentido de al mismo tiempo que) el paisaje industrial que Moglia Barth había mostrado dos años antes en Riachuelo. Pero, con Amalia, Moglia Barth elige que Barracas también sea contemporánea de la utopía barrial que postula el texto de Mármol.

La condición de posibilidad para la postulación de esa utopía en la novela es lo que Mármol llama la "ficción calculada" (1), una operación política que consiste en narrar los hechos del presente como si hubieran sucedido en un tiempo remoto, como si la barbarie rosista fuera un fenómeno propio del oscurantismo de la Edad Media o de la época de la colonia española. Ricardo Piglia ("Escenas de la novela argentina") sostiene que este procedimiento puede inscribirse dentro de una tradición nacional, de la que también formaría parte el Facundo y según la cual nuestra temporalidad es no cronológica: los argentinos nunca somos contemporáneos del presente. ¿De qué somos, entonces, contemporáneos? La respuesta de Piglia es que somos contemporáneos de una comunidad imaginaria que se considera ya perdida y que solo podrá recuperarse en un futuro utópico. Desde esta perspectiva, la nostalgia comunitaria sería inherente no solo a la ficción calculada sino a la idea misma de argentinidad.

La nostalgia y la utopía comunitarias en la película, por su parte, también entrañan una reflexión política. Al respecto, es preciso recordar que en 1936 Buenos Aires estaba adoptando una forma conclusa y definitiva, con la rectificación del Riachuelo y la concreción de la avenida General Paz, que permiten circunscribir el área de acción municipal. Pero al remitirnos a la Buenos Aires de 1840, que en la novela "se descubre informe, $[\ldots]$ inmensa" (Mármol, 2004 36; el énfasis es mío), Moglia Barth repolitiza la zona del Bajo y recupera la tensión que esta zona habría mantenido entre su carácter de límite y umbral en la obra y la vida de Mármol. Como anota Mariano de Vedia y Mitre en un artículo publicado en La Nación en 1917, luego de salir de la cárcel y antes de exiliarse, Mármol se refugia para tramar la huida en la casa de su tía María Mármol de Terrada, ubicada en el Riachuelo de Barracas. Para Mármol, por lo tanto, Barracas funciona como el umbral que posibilita 
el pasaje al exilio. No obstante, ya desde el primer capítulo, en la novela las riberas del río definen los límites de la ciudad letrada. Aunque los protagonistas la imaginan como umbral, Barracas acaba siendo el límite que frustra el pasaje. La película, en tanto, al reinstalar esta tensión en 1936, mientras la ciudad fija sus límites, habilita a volver a pensar la zona de Barracas como umbral (una lectura que De Vedia y Mitre puede aceptar como biógrafo de Mármol en 1917, pero ya no como intendente de Buenos Aires en los años treinta). Un texto sobreimpreso que enmarca la historia al comienzo del filme subraya este carácter de umbral de la parte baja de la ciudad: "Por las costas del Río de la Plata se huía de Buenos Aires, alejándose del puñal que armaba el odio o para engrosar el ejército que se aprestaba a luchar contra Juan Manuel de Rosas". E imaginar la zona de Barracas como un umbral en ese momento suponía un cuestionamiento al repliegue local del barrio característico del tango, concebido -según Gorelik- como una "manifestación en escala del repliegue de la ciudad sobre sí misma que produce De Vedia" $(451) .{ }^{15}$

En una dirección similar parece apuntar César Aira cuando sostiene que "la Historia de la Argentina es una historia municipal" y que Amalia es una novela topográfica, puesto que vuelve a Buenos Aires "un objeto, una maqueta, una miniatura, cosa mentale" (32). Esta imagen municipal de la ciudad contaba con un fuerte arraigo en 1936. La inscripción alusiva a la federalización de Buenos Aires que aún hoy puede leerse en el obelisco es un indicador de ello. Con todo, bajo la forma de un homenaje a la fundación del municipio en 1880, esta inscripción encubre el deseo de vincular una conquista de la ciudad con otra, en un proceso repleto de discontinuidades pero que se pretende sin fisuras. La conformación definitiva del municipio se descubriría entonces como el revés inmunitario de la comunidad, la figura que protege la ciudad del contagio con el exterior.

15 Hay así en la versión cinematográfica de Amalia un uso político de la apoliticidad del barrio, en tanto espacio abstracto de construcción de la ciudadanía e imaginario moderado sobre la transformación social, orientado a la búsqueda de consenso (Gorelik 438-439). Teniendo en cuenta la filiación radical de Moglia Barth -tematizada en algunas de sus películas, como El 90 (1948), Boina blanca (1941) y Edición extra (1949)-, es preciso resaltar que esta preocupación coincide, en 1936, con el reingreso pleno del radicalismo al juego electoral y su victoria en la Capital Federal. Con esta aclaración no se trata, desde luego, de reducir lo estético a lo político, sino de explorar los modos en que un hecho de la política puede iluminar la elaboración estética de una cuestión como la tensión entre modernización y reformismo, que atraviesa ambas esferas. 
Ambas nociones, de hecho, se encuentran ligadas en su etimología. La raíz del término municipium es la que está presente en la idea de comunidad, tal como ha sido examinada por Roberto Esposito. Se trata del munus, entendido como una falta, deuda u obligación (Esposito, Communitas 28). Los municipes serían así aquellos que asumen la deuda (munus capessere) y, en consecuencia, quedan mancomunados por la falta de asociación. Según Esposito, las respuestas de inmunidad surgen, justamente, para liberar a los miembros de una comunidad de esa falta que los destituye de su subjetividad. En tal sentido, en la obra de Moglia Barth, esa réplica en miniatura de la ciudad que constituye el barrio pareciera estar atravesada por la idea de protección inmunitaria. En Tango!, por ejemplo, cuando Tita Merello cantaba:

No salgas de tu barrio, sé buena muchachita, casate con un hombre que sea como vos y aun en la miseria sabrás vencer tu pena y ya llegará un día en que te ayude Dios

Moglia Barth sostenía una resistencia casi religiosa a establecer lazos comunitarios fuera de los límites del barrio (el peligro para la muchachita sería caer en manos de un "niño engominado" que le enseñe "todos sus vicios" y haga de ella "este despojo").

Tres años más tarde, contra su pretendido afán de distanciarse de ese imaginario tanguero a través de una costosa película de época, Moglia Barth lo reelabora -al menos parcialmente- en Amalia. La protagonista del filme, luego de rechazar las insinuaciones del comandante Mariño, corre a su alcoba y se refugia rezando a la virgen. La sucesión de primeros planos de Herminia Franco y planos detalles de la virgen sugiere, asimismo, la idea de una Amalia virginal, que no puede unirse con un federal, sino que debe casarse con un hombre que sea como ella, es decir, unitario. La insistencia en la religión católica como mecanismo de inmunización para la facción unitaria se reitera durante la escena del casamiento con Eduardo, en la que se destaca la presencia de la cruz al ubicarse en el centro del encuadre. Si bien la confrontación entre lo angelical y lo demoníaco también estaba presente en la novela (el capítulo noveno de la primera parte, por ejemplo, se titula "El ángel o el diablo"), la película enfatiza la lectura católica de esa oposición que para Mármol se inscribía más bien dentro de una concepción romántica del mundo. Además de entenderla como una probable respuesta al corpus de ideas católicas y nacionalistas impulsadas 
en la década del treinta desde el recientemente creado Instituto Cinematográfico Argentino, ${ }^{16}$ esta decisión de Moglia Barth puede abordarse en clave inmunitaria, como una forma de desatar la representación maniquea de las polarizaciones entre federales y unitarios.

Así, como contraparte, la acción de la Mazorca aparece demonizada en el filme desde el afiche mismo: Cuitiño, mimetizado con el fondo rojo, desde un vértice amenaza, puñal en mano, la escena idílica y luminosa que protagonizan Amalia y Eduardo. Esta imagen supone un contraste con el afiche de Riachuelo -minuciosamente estudiado por Garramuño (217)-, que escenifica las tensiones entre el ambiente portuario, moderno, industrial y tecnológico, por un lado, y los personajes típicos del barrio local, por el otro. En el caso de aquel filme, las tensiones entre lo local y lo moderno en buena medida eran resueltas por Moglia Barth gracias a la adecuación de la historia a las normas del género (el sainete). En Amalia, en cambio, las tensiones eran de otro tipo. En principio, eran anteriores a la constitución del Estado nacional y -como indica una de las placas que abren el filme- "engendraban odios y rencores y separaban [a] los hermanos argentinos en Federales y Unitarios". ${ }^{17}$ Lo que encadena a unos y otros sería, pues, la falta de asociación, que se manifiesta en diversos mecanismos inmunitarios destinados a deshacerla: para los unitarios, la religión católica; para los federales, la acción de la Mazorca, en tanto fuerza municipal que actúa como agente de inmunización. En la película esta última noción se refuerza a través de la importancia otorgada al personaje de María Josefa, que es quien trama las alianzas entre los mazorqueros y las clases populares. Sus risas diabólicas, a la vez, en una grotesca sobreactuación de las nuevas posibilidades que ofrecía la llegada

16 Para un examen detallado de las medidas promovidas por el Instituto Cinematográfico Argentino durante esos años y sus relaciones con la Iglesia católica, recomendamos consultar el libro Cine y peronismo. El estado en escena, de Clara Kriger (27-32).

17 Otro punto interesante de comparación entre los mecanismos inmunitarios de ambos filmes es la posición respecto de los movimientos migratorios: si Riachuelo comienza con el famoso personaje de Berretín (interpretado por Luis Sandrini) mofándose de las dificultades lingüísticas de los inmigrantes y marineros del puerto, Amalia, en cambio, construye una imagen nostálgica de una Buenos Aires anterior a las grandes oleadas inmigratorias, en la que el problema es, contrariamente, la emigración: "Es necesario que paremos esta copiosa emigración que va a buscar lejos una libertad que puede encontrar aquí cuando alce su brazo armado sobre la cabeza del tirano", dice Daniel en un parlamento tomado casi literalmente de la novela. En ambas películas, de todas formas, lo que está en juego es la supervivencia de una comunidad nacional que se siente amenazada por diversas formas de la barbarie. 
del cine sonoro (manejadas, sin embargo, con destreza por Moglia Barth en otros pasajes ${ }^{18}$ ), la configuran como antagonista evidente de Amalia. En las escenas que transcurren en el jardín de la quinta de Barracas, asimismo, el idilio es amenazado por la irrupción de las clases populares, encarnadas en la figura de la criada negra escondida entre los arbustos, que envía María Josefa para espiar a los amantes. Otro momento significativo en el que se puede apreciar esta lectura de la ciudad en tensión se produce cuando don Cándido (el maestro de la infancia de Daniel) camina por las calles del Bajo en dirección a la casa de su exalumno. A diferencia de la tendencia habitual en el cine de la época, ${ }^{19}$ esta escena no fue filmada en estudios sino en una calle del Bajo, con sus construcciones coloniales, de manera que las imágenes adquieren un valor cuasidocumental. La candidez de la música, así como la presencia de los árboles y de un vendedor que pasa con un carro tirado por bueyes, resaltan la cordialidad de esta típica escena barrial, que a mediados de la década de 1930, sin embargo, comenzaría a verse interrumpida por la emergencia de Barracas como espacio de industrialización. Pero enseguida la película nos devuelve a 1840, cuando don Cándido se cruza con una criada y su pequeña hija, que le hace una mueca burlona. Las dos fuerzas en tensión, federales y unitarios, posteriormente colisionan hacia el final del relato cuando irrumpe la Mazorca en la escena del casamiento, pero la contradicción sería solo aparente ya que ambas obedecen a una misma lógica.

18 Me refiero, puntualmente, a la notable primera secuencia del filme. Allí Moglia Barth despliega un uso dramático de la música y un manejo preciso de la elipsis, para mostrar la lucha entre unitarios y federales a orillas del río. La secuencia luego desemboca en la apacible quinta de Amalia, donde mediante el empleo del sonido fuera de campo percibimos la llegada de Eduardo y Daniel, quienes golpean la puerta de la casa.

19 Véase, al respecto, el artículo de Homero Manzi publicado en el diario El Sol del 31 de octubre de 1939, bajo el título "El paisaje argentino espera su puesto de primer actor en nuestra cinematografía". Allí Manzi reivindica, en términos bastante críticos, la importancia de filmar en locaciones reales en lugar de hacerlo en "estudios petulantes". Entre otras cosas, afirma: "En Melgarejo (1937), había una estancia con tierra sobre el parquet [...]. En Puerto Nuevo (1936) un arrabal de utilería". Estas dos películas eran bastante afines a Amalia, no solo por una cuestión de cercanía temporal sino porque eran producciones de Argentina Sono Film. Melgarejo, además, fue dirigida por el propio Moglia Barth. Asimismo, el espacio del arrabal en Puerto Nuevo -que hoy reconoceríamos como una villa miseria-, por su falta de planeamiento urbanístico se opone al trazado regular de las calles de la ciudad antigua de Amalia, como si el filme de Moglia Barth buscara separarse, también en este sentido cartográfico, del imaginario arrabalero de los suburbios, los malevos y el tango. 
Esta lógica inmunitaria encuentra su contrapunto en el hecho de que tanto la novela como el filme imaginan, junto con los exiliados, una comunidad fuera de los límites territoriales de la patria: "En Montevideo será mi felicidad pero en Buenos Aires está mi deber", dice el personaje de Daniel en la película. En este sentido, la utopía urbana y barrial que el filme retoma de la novela comporta un contraste anacrónico con la ciudad industrial de límites fijos que en 1936 deviene epítome de la nacionalidad. Una argentinidad que, recuperando la cita inicial de Sarlo, ya no es una causa y un programa, como en la época de Mármol, sino que se pretende cerrada y fijada, pero esconde fallas profundas. Precisamente, en ese lugar vacío o fallado de la nacionalidad se instala el filme, para imaginar otra nación posible que asume la forma de una doble búsqueda. Búsqueda humana, por un lado, ya que las imágenes alternativas de la nación deben inventarse un público, de la misma manera que la nación imaginada un pueblo; y búsqueda geográfica, por el otro, ya que las imágenes alternativas de la nación requieren un escenario, al igual que la nación imaginada un territorio.

De esta manera, los personajes de Amalia habitan ese lugar fallado que desde la frustrada fundación de Buenos Aires en 1536 y aún hoy constituye la zona del Bajo, cuyo escenario principal es el Riachuelo. Espacio de la miseria pero también de las promesas incumplidas, el Riachuelo es sobre todo una zona residual. De ahí que, en un sentido tanto espacial como temporal de la concomitancia, podamos imaginar que junto con los desechos industriales y humanos, en esa zona liminar de la ciudad habitan los residuos de la literatura, del cine y de la historia.

\section{Obras citadas}

Aira, César. "Amalia". Cuadernos Hispanoamericanos

743 (mayo de 2012): 25-35. Impreso.

"Amalia". El Pueblo. Buenos Aires, 9 de julio de 1936. Impreso.

"Amalia, el romance histórico de Mármol, se estrena hoy en el

Monumental". La Capital. Rosario, 8 de julio de 1936. Impreso.

"Amalia". Heraldo del Cinematografista. Buenos Aires, 8 de julio de 1936. Impreso.

Anderson, Benedict. Comunidades imaginadas. Reflexiones sobre el origen y la difusión

del nacionalismo. Buenos Aires: Fondo de Cultura Económica, 2011. Impreso.

Barthes, Roland. Cómo vivir juntos. Simulaciones novelescas de algunos

espacios cotidianos. Buenos Aires: Siglo Veintiuno, 2003. Impreso.

Batticuore, Graciela. La mujer romántica. Lectoras, autoras y escritores en

la Argentina: 1830-1870. Buenos Aires: Edhasa, 2005. Impreso. 
Caras y Caretas xxxix-1971. Buenos Aires, 11 de julio de 1936. Impreso.

Castellanos, Julio. Amalia. Drama histórico en siete actos adaptado de la novela de José Mármol. Bambalinas 6 (Buenos Aires, 1918): s.p. Impreso.

Curia, Beatriz. "Problemas textuales de Amalia de José

Mármol". Incipit II (1982): 61-83. Impreso.

Dabove, Juan Pablo. Nightmares of the Lettered City. Banditry and Literature in Latin America, 1816-1929. Pittsburgh: University of Pittsburgh, 2007. Impreso.

Dámaso Martínez, Carlos. Capítulo. La historia de la literatura argentina. T. 12. Buenos Aires: CEAL, 1979. Impreso.

De Vedia y Mitre, Mariano. "José Mármol". La Nación. 2 al 9 diciembre de 1917. Impreso.

Esposito, Roberto. Categorías de lo impolítico. Buenos Aires: Katz, 2006. Impreso. Esposito, Roberto. Communitas. Origen y destino de la comunidad. Buenos Aires: Amorrortu, 2003. Impreso.

"Estrenose ayer Amalia, película adaptada de la novela de José Mármol". La Prensa. Buenos Aires, 9 de julio de 1936. Impreso.

Garramuño, Florencia. Modernidades primitivas. Tango, samba y nación. Buenos Aires: Fondo de Cultura Económica, 2007. Impreso.

Ghiano, Juan Carlos. Contribución a la bibliografía de fosé Mármol. La Plata: Universidad Nacional de La Plata, 1972. Impreso.

Gómez, Martín. "Amalia". Caras y Caretas. Buenos Aires, 21 de mayo de 1904. Impreso. Gorelik, Adrián. La grilla y el parque. Espacio público y cultura urbana en Buenos Aires, 1887-1936. Buenos Aires: Universidad Nacional de Quilmes, 2004. Impreso.

Halperin Donghi, Tulio. El revisionismo histórico argentino como visión decadentista de la historia. Buenos Aires: Siglo Veintiuno, 2005. Impreso.

Halperin Donghi, Tulio. Una nación para el desierto argentino. Buenos Aires: CEAL, 1995. Impreso.

Imágenes. 17 de julio de 1936. Impreso.

Karush, Matthew. Cultura de clase. Radio y cine en la creación de una argentina dividida (1920-1946). Buenos Aires: Ariel, 2013. Impreso.

Kriger, Clara. Cine y peronismo. El estado en escena.

Buenos Aires: Siglo XXI, 2009. Impreso.

"La discutida figura histórica de Rozas aparece en la adaptación de Amalia". La comuna. Tres Arroyos, 13 de agosto de 1936. Impreso.

"La versión de la novela de Mármol es un acierto directivo de Moglia Barth". Crítica. Buenos Aires, 9 de julio de 1936. Impreso. 
Laera, Alejandra. "El ángel y el diablo: ficción y política en Amalia".

Letras y divisas. Ensayos sobre literatura y rosismo. Comp. Cristina

Iglesia. Buenos Aires: Santiago Arcos, 2004. 97-109. Impreso.

Laera, Alejandra. El tiempo vacío de la ficción. Las novelas argentinas de Eduardo Gutiérrez y Eugenio Cambaceres. Buenos Aires:

Fondo de Cultura Económica, 2004. Impreso.

Manzi, Homero. "El paisaje argentino espera su puesto de primer actor en nuestra cinematografía". El Sol. 31 octubre 1939. Impreso.

Mármol, José. Amalia. Buenos Aires: Sopena, 1932. Impreso.

Mármol, José. Amalia. México: Porrúa, 2004. Impreso.

Nancy, Jean-Luc. "Conloquium". Communitas. Origen y destino de la comunidad. Roberto Esposito. Buenos Aires: Amorrortu, 2003. 9-19. Impreso.

Neifert, Agustín. Rosas y su época en el cine argentino. Buenos Aires: Ediciones Fabro, 2012. Impreso.

Piglia, Ricardo. "Escenas de la novela argentina". 1 de septiembre de 2012. https://www.youtube.com/watch?v=mKoENCrDBoQ. Video.

"Por su realización, Amalia se destaca sobre el cuadro de las últimas películas criollas". Noticias gráficas. Buenos Aires, 9 de julio de 1936. Impreso.

Prieto, Adolfo. El discurso criollista en la formación de la Argentina moderna. Buenos Aires: Siglo XXI, 2006. Impreso.

Saccomano, Guillermo y Ema Wolf. El folletín. Buenos Aires: CEAL, 1972. Impreso. Sarlo, Beatriz. El imperio de los sentimientos. Buenos Aires: Norma, 2004. Impreso.

Sarlo, Beatriz. Una modernidad periférica: Buenos Aires 1920 y 1930. Buenos Aires: Nueva Visión, 2007. Impreso.

Sommer, Doris. Ficciones fundacionales. Las novelas nacionales de América Latina. Bogotá: Fondo de Cultura Económica, 2004. Impreso.

Torre, Claudia. "Buenos Aires, cartografía punzó: Amalia, de José Mármol”. Letras y divisas. Ensayos sobre literatura y rosismo. Comp. Cristina Iglesia. Buenos Aires: Santiago Arcos, 2004. 77-85. Impreso.

Viñas, David. "Mármol y los dos ojos del romanticismo". Literatura argentina y realidad política. Buenos Aires: CEAL, 1982. Impreso. 